\title{
Emphysema is associated with increased inflammation in lungs of atherosclerosis-prone mice by cigarette smoke: implications in comorbidities of COPD
}

\author{
Gnanapragasam Arunachalam, Isaac K Sundar, Jae-woong Hwang, Hongwei Yao, Irfan Rahman*
}

\begin{abstract}
Background: Chronic obstructive pulmonary disease is associated with numerous vascular effects including endothelial dysfunction, arterial stiffness and atherogenesis. It is also known that a decline in lung function is associated with increased cardiovascular comorbidity in smokers. The mechanism of this cardiopulmonary dual risk by cigarette smoke (CS) is not known. We studied the molecular mechanisms involved in development of emphysema in atherosclerosis-prone apolipoprotein E-deficient $\left(\mathrm{ApoE}^{-1}\right)$ mice in response to $\mathrm{CS}$ exposure.

Methods: Adult male and female wild-type (WT) mice of genetic background C57BL/6J and $\mathrm{ApoE}^{-1-}$ mice were exposed to CS, and lung inflammatory responses, oxidative stress (lipid peroxidation products), mechanical properties as well as airspace enlargement were assessed.

Results and Discussion: The lungs of $\mathrm{ApoE}^{-/}$mice showed augmented inflammatory response and increased oxidative stress with development of distal airspace enlargement which was accompanied with decline in lung function. Interestingly, the levels and activities of matrix metalloproteinases (MMP-9 and MMP-12) were increased, whereas the level of eNOS was decreased in lungs of CS-exposed ApoE ${ }^{-/-}$mice as compared to air-exposed ApoE $^{-1-}$ mice or CS-exposed WT mice.

Conclusion: These findings suggest that CS causes premature emphysema and a decline of lung function in mice susceptible to cardiovascular abnormalities via abnormal lung inflammation, increased oxidative stress and alterations in levels of MMPs and eNOS.
\end{abstract}

\section{Background}

Chronic obstructive pulmonary disease (COPD) is characterized by chronic airflow limitation resulting from excessive airway inflammatory response mediated by cigarette smoke (CS). Comorbidities such as cardiovascular disease, diabetes, lung cancer, and osteoporosis are more prevalent in smokers and patients with COPD [1-3]. Recent studies have shown that smokers with altered forced expiratory volume in one second $\left(\mathrm{FEV}_{1}\right)$ and airflow limitation are associated with arterial stiffness, exaggerated atherosclerosis and vice-versa $[2,4,5]$. Growing evidence also indicates that inflammation,

\footnotetext{
* Correspondence: Irfan_Rahman@urmc.rochester.edu

Department of Environmental Medicine, Lung Biology and Disease Program, University of Rochester Medical Center, Rochester, NY, USA
}

endothelial dysfunction and oxidative modification of lipids play an important role in the pathogenesis of atherosclerosis and COPD $[3,6,7]$. In addition to CS, alcohol consumption is also one among the important contributing factors involved in the pathogenesis of COPD and atherosclerosis and their co-morbidities [8,9].

Apolipoprotein E-deficient $\left(\mathrm{ApoE}^{-/-}\right)$mice develop atherosclerosis due to an accumulation of cholesterol ester-enriched particles in the blood resulting from a lack of triglyceride and cholesterol metabolism/lipid transport [10]. These mice have a shorter life-span and age faster than wild-type counterparts [11]. CS exposure to $\mathrm{ApoE}^{-/-}$mice promotes arterial thrombosis and modulates the size and composition of neointimal lesions/ thickening [12], which is associated with increased

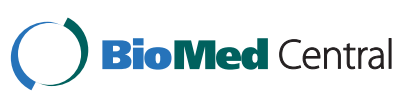


oxidative stress, reduced glutathione levels and mitochondrial damage leading to atherosclerotic lesion formation [6,13-17]. Massaro and Massaro have recently shown that these mice have an impaired pulmonary morphology and functional phenotype with a rapid decline in lung function as they age [18]. However, the underlying molecular mechanism of the pulmonary phenotype was not studied. We used the $\mathrm{ApoE}^{-1-}$ mice, which are prone to develop atherosclerosis $[19,20]$, to understand the molecular mechanism of pulmonary phenotype in response to CS exposure, as well as to study the concept of accelerated decline in lung function and aging in cardiopulmonary comorbid conditions. We determined the inflammatory response, oxidative stress (lipid peroxidation products), levels/activities of matrix metalloproteinases (MMP-9 and MMP-12) and NAD ${ }^{+}$ dependent deacetylase sirtuin 1 (SIRT1) which is shown to regulate endothelial nitric oxide synthase (eNOS) activity (endothelial function) in lungs of $\mathrm{ApoE}^{-1-}$ mice exposed to CS.

\section{Methods}

\section{Reagents}

Unless otherwise stated, all biochemical reagents used in this study were purchased from Sigma Chemicals Co., St. Louis, MO, USA. Antibodies used to detect proteins include mouse specific SIRT1 and eNOS (Cell Signaling, Danvers, MA), MMP-9 and MMP-12 (Santa Cruz Biotechnology, Santa Cruz, CA) for western blotting and immunoprecipitation.

\section{Animals}

Adult male and female wild-type (WT) mice of genetic background C57BL/6J and $\mathrm{ApoE}^{-/-}$mice $[19,20]$ (Strain number, B6.129P2-Apoe ${ }^{\text {tm1Unc }} /$ J; stock number, 002052, backcrossed to C57BL/6J for 10 generations, Jackson Laboratory, Bar Harbor, ME) were housed in the inhalation facility of the University of Rochester. These mice were fed with regular standard Chow diet during housing and experimental procedures. $\mathrm{ApoE}^{-/-}$mice showed obvious signs of atherosclerotic lesions in the aortic sinus and ascending aorta after feeding with Chow diet at 24 weeks of age with an early onset of signs seen after approximately 3-4 months of age (Jackson Lab). ApoE ${ }^{-1-}$ mice develop atherosclerotic plaques at 2-3 months after feeding with a high-fat Western-type diet [20]. All experimental protocols described in this study were approved by the animal research committee of the University of Rochester.

\section{CS exposure}

Adult mice (12 weeks old, body weight ranging from 30$40 \mathrm{~g}$, male and female) were exposed to CS for 3 days using Baumgartner-Jaeger CSM2082i automated cigarette smoking machine $(\mathrm{CH}$ Technologies, Westwood, NJ) $[21,22]$. The smoke was generated from 3R4F research cigarettes (University of Kentucky, Lexington, KY). Mainstream CS was diluted with filtered air, and directed into the exposure chamber. Monitoring of the CS exposure (TPM per cubic meter of air, $\mathrm{mg} / \mathrm{m}^{3}$ ) was performed in real-time using MicroDust Pro-aerosol monitor (Casella CEL, Bedford, UK) and verified daily by gravimetric sampling. The smoke concentration was set at a nominal value of approximately $300 \mathrm{mg} / \mathrm{m}^{3}$ TPM by adjusting the flow rate of the dilution air $[21,22]$. The control mice were exposed to filtered air in an identical manner.

\section{Bronchoalveolar lavage and tissue harvest}

The mice were intraperitoneally injected with $100 \mathrm{mg} / \mathrm{kg}$ body weight of pentobarbiturate (Abbott laboratories, Abbott Park, IL) and killed by exsanguination. The lungs were lavaged three times with $0.6 \mathrm{ml}$ of $0.9 \%$ sodium chloride and removed en bloc. The bronchoalveolar lavage (BAL) fluid cell pellet was resuspended in saline, and the total cell number was counted with a hemocytometer. Differential cell count (500 cells/slide) was performed on cytospin-prepared slides (Thermo Shandon, Pittsburgh, PA) stained with Diff-Quik (Dade Bering, Newark, DE).

\section{Cytokine analysis}

The levels of proinflammatory mediators such as monocyte chemoattractant protein-1 (MCP-1) and chemokine keratinocyte chemoattractant $(\mathrm{KC})$ in lung homogenates were measured by ELISA using respective duo-antibody kits (R\&D Systems, Minneapolis, MN) according to the manufacturer's instructions.

\section{Immunohistochemical staining for tissue macrophages}

Immunohistochemical staining for macrophages in lung sections was performed as described previously [21,22]. The number of Mac-3-positive cells in each lung section ( 5 random microscopic fields per lung section in 3 different sections) was counted manually at $\times 200$ magnification and averaged.

\section{Lipid peroxidation products assay in lung homogenate} The right lung lobe was homogenized with ice-cold $20 \mathrm{mM}$ Tris- $\mathrm{HCl}(\mathrm{pH} 7.4)$ and centrifuged at 3,000 $\mathrm{g}$ at $4^{\circ} \mathrm{C}$ for $10 \mathrm{~min}$, and the supernatants were collected. Butylated hydroxytoluene ( $5 \mathrm{mM})$ was added to the supernatant to prevent further peroxidation, and the samples were immediately frozen in liquid nitrogen. Lipid peroxidation products [malondialdehyde (MDA) and 4-hydroxy-2-nonenal (4-HNE)] were measured using a lipid peroxidation kit (Enzo Life Sciences, PA) according to the manufacturer's instructions [22]. 


\section{Measurement of lung mechanical properties}

Lung mechanical properties were determined using Scireq Flexivent apparatus (Scireq, Monteral, Canada). The dynamic lung compliance and lung resistance were measured in mice anesthetized by sodium pentobarbital (50 $\mathrm{mg} / \mathrm{kg}$, intraperitoneally) and paralyzed with pancuronium $(0.5 \mathrm{mg} / \mathrm{kg}$, intraperitoneally). A tracheotomy was performed and an 18-guage cannula was inserted 3 $\mathrm{mm}$ into an anterior nick in the exposed trachea and connected to a computer controlled rodent ventilator. Initially, the mice were ventilated with room air (150 breaths $/ \mathrm{min}$ ) at a volume of $10 \mathrm{ml} / \mathrm{kg}$ body mass. After 3 minutes of ventilation, measurement of lung mechanical properties were initiated by the computer generated program to measure dynamic lung compliance and resistance. These measurements were repeated three times for each animal.

\section{Hematoxylin and Eosin (H\&E) staining and mean linear intercept analysis}

Mouse lungs (which had not been lavaged) after CS exposure were inflated by $1 \%$ low-melting agarose at a pressure of $25 \mathrm{~cm} \mathrm{H}_{2} \mathrm{O}$, and then fixed with neutral buffered formalin. Tissues were embedded in paraffin, sectioned $(4 \mu \mathrm{m})$, and stained with hematoxylin and eosin (H\&E). The alveolar size was estimated from the mean linear intercept (Lm) of the airspace which is a measure of airspace enlargement/emphysema. Lm was calculated for each sample based on 10 random fields observed at a magnification of $\times 200$ using cross-lines as described previously $[21,22]$.

\section{Immunoblotting}

Proteins $(20 \mu \mathrm{g})$ from lung tissue homogenates were used for immunoblotting as described previously [21-24]. In brief, protein was electrophoresed on 7.5\% SDS-PAGE gel and transblotted on nitrocellulose membrane (Amersham Biosciences, Piscataway, NJ). Membranes were blocked with $5 \%(\mathrm{w} / \mathrm{v})$ non-fat milk in PBS containing $0.1 \%(\mathrm{v} / \mathrm{v})$ Tween 20 and then incubated with anti-SIRT1, anti-eNOS, anti-MMP-9 or anti-MMP12 antibodies. After washing, bound antibody was detected using anti-rabbit/anti-mouse antibody linked to horseradish peroxidase and bound complexes were detected using enhanced chemiluminescence (Perkin Elmer, Waltham, MA). Protein levels were measured by BCA kit as per the manufacturer's instructions using BSA as standards (Thermo Scientific, Rockford, IL).

\section{SIRT1 deacetylase activity assay}

SIRT1 activity was assayed using a deacetylase colorimetric activity assay kit according to the manufacturer's instructions (Biomol International, Plymouth Meeting, PA). Briefly, SIRT1 was immunoprecipitated from whole lung homogenates $(100 \mu \mathrm{g}$ protein $)$. After the final washing, Color de Lys substrate reagent and $\mathrm{NAD}^{+}$were added to the SIRT1 conjugated beads and incubated at $37^{\circ} \mathrm{C}$ for $80 \mathrm{~min}$. The substrate-SIRT1 mixture was then placed on a 96-well plate, and the Color de Lys developer reagent was added to the wells at $37^{\circ} \mathrm{C}$ for $20 \mathrm{~min}$. The plate was then read at $405 \mathrm{~nm}$ using a spectrophotometer (Model 680 microplate reader, Bio-Rad, Hercules, CA).

\section{MMPs activity assay by zymography}

The zymography was performed to determine the activity of MMPs in mouse lung as described previously [25]. Briefly, lung tissues were homogenized in $400 \mu$ l lysis buffer ( $50 \mathrm{mM}$ Tris-HCl, $\mathrm{pH} 7.4$, with protease inhibitors) on ice. One hundred micrograms of protein was then mixed with equal volume sample buffer $(80 \mathrm{mM}$ Tris- $\mathrm{HCl}, \mathrm{pH} 6.8$, 4\% SDS, $10 \%$ glycerol, $0.01 \%$ bromophenol blue) and then loaded on a 7.5\% SDS-polyacrylamide gel containing $1 \mathrm{mg} / \mathrm{ml}$ gelatin which was overlaid with 5\% stacking gel. After electrophoresis, gels were rinsed in distilled water, washed three times for $15 \mathrm{~min}$ utes each in $150 \mathrm{ml} \mathrm{2.5 \%}$ Triton X-100 solution. Gels were then incubated in $100-150 \mathrm{ml}$ of $50 \mathrm{mM}$ Tris- $\mathrm{HCl}$ (pH 7.5), $10 \mathrm{mM} \mathrm{CaCl}_{2}, 1 \mu \mathrm{M} \mathrm{ZnCl}_{2}, 1 \%$ Triton X-100 and $0.02 \% \mathrm{NaN}_{3}$. After incubation, gels were stained with $100 \mathrm{ml}$ Coomassie blue R-250 for $3 \mathrm{~h}$ and then destained $1 \mathrm{~h}$ with destaining solution (50\% methanol, $10 \%$ acetic acid). Gels were washed in distilled water for 20 minutes and then scanned. The intensity of bands was quantified using image J software (Version 1.41, National Institutes of Health, Bethesda, MD, USA).

\section{Statistical analysis}

Data were presented as means \pm SEM. Statistical analysis of significance was calculated using one-way analysis of variance followed by post hoc test for multigroup comparisons using Stat View software. $P<0.05$ was considered as significant.

\section{Results}

ApoE ${ }^{-/-}$mice are susceptible to increased lung inflammatory cell influx in response to CS

Augmented inflammatory response in the lung from environmental stress or toxicants results in the activation of inflammatory cascades in microvasculature and vessel walls leading to a potentiation of atherogenesis $[12,13,26,27]$. Atherogenic prone $\mathrm{ApoE}^{-1-}$ were exposed to CS for 3 days, and the number of neutrophils and macrophages in BAL fluid as well as in the lungs were determined. CS exposure led to a higher number of neutrophil influx in BAL fluid of $\mathrm{ApoE}^{-1-}$ mice as compared to WT mice (Fig. 1A). However, CS exposure significantly decreased the number of macrophages in BAL fluid of $\mathrm{ApoE}^{-/-}$mice, but not in WT mice (Fig. 1B). Interestingly, the macrophage infiltration in lung interstitium of 


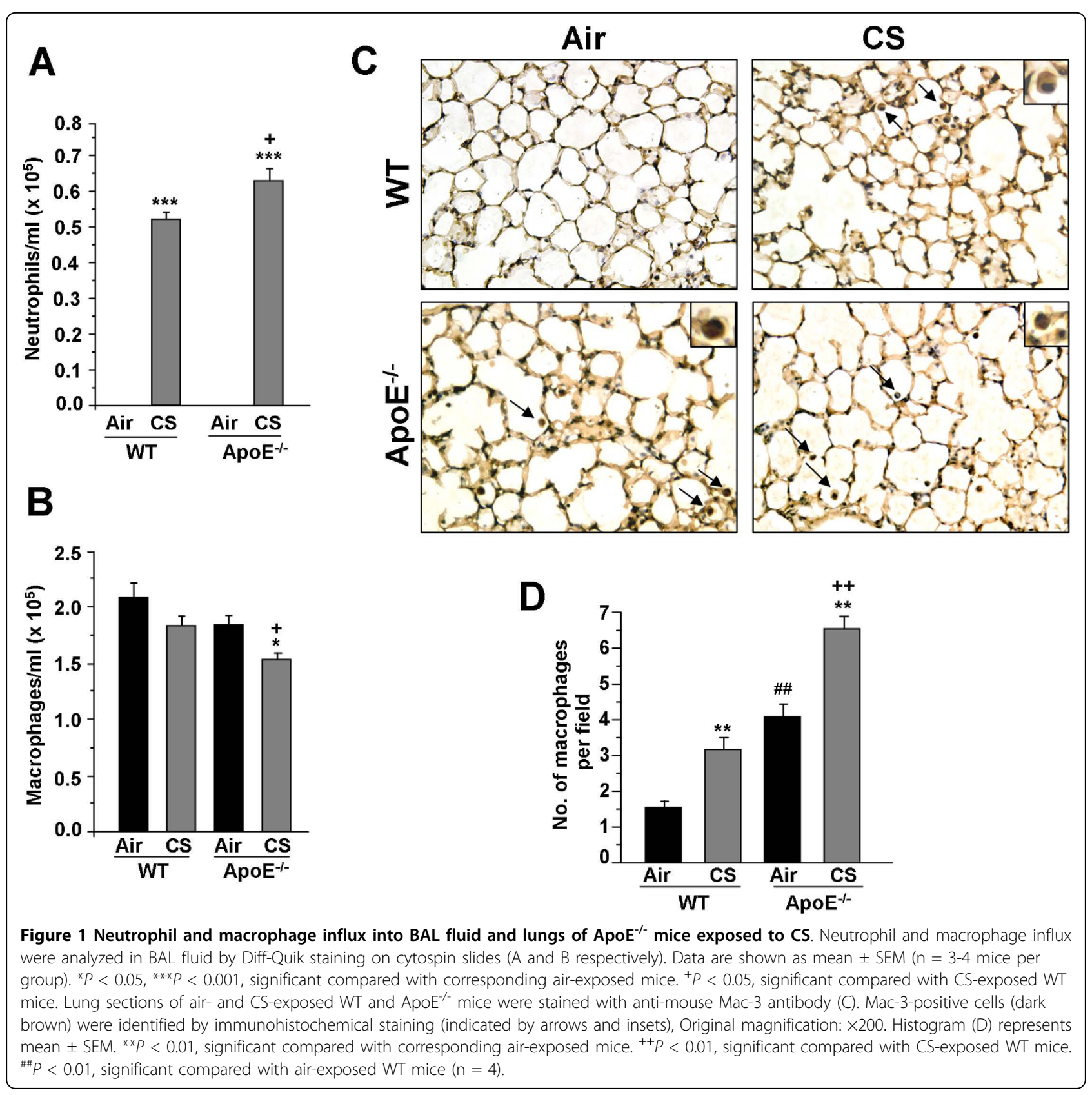

air-exposed $\mathrm{ApoE}^{-/-}$mice was significantly increased as compared to air- and CS-exposed WT mice. This was augmented in CS-exposed ApoE A $^{-/-}$mice (Fig. 1C, D).

\section{CS exposure augments the proinflammatory cytokine levels in lungs of $\mathrm{ApoE}^{-/-}$mice} In order to confirm whether the inflammatory cell influx was associated with proinflammatory cytokine release in $\mathrm{ApoE}^{-/-}$mice, the levels of proinflammatory mediators, such as MCP-1 and KC, which can recruit macrophages and neutrophils in the lung, were measured in lung homogenates of air- and CS-exposed WT and $\mathrm{ApoE}^{-/-}$ mice. CS-exposure to ApoE ${ }^{-/-}$mice significantly increased the levels of $\mathrm{MCP}-1$ and $\mathrm{KC}$ as compared to CS-exposed WT mice (Fig. 2A, B). These results suggest that increased levels of MCP-1 and $\mathrm{KC}$ may contribute to enhanced macrophage and neutrophil influx in the lungs of $\mathrm{ApoE}^{-/-}$mice after CS exposure.

\section{ApoE $^{-/-}$mice lung shows increased oxidative stress as} lipid peroxidation products (4-HNE and MDA) in response to CS

We previously showed that CS-induced oxidative stress is involved in the development of emphysema and 

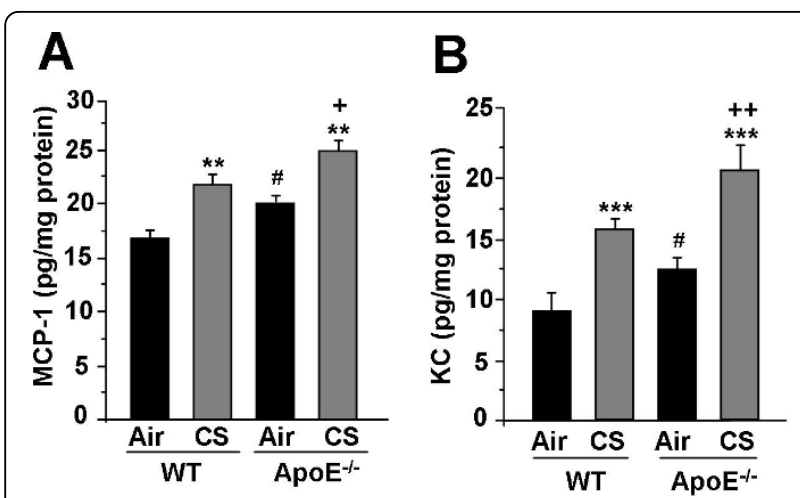

Figure 2 Levels of pro-inflammatory mediators in lungs of $\mathrm{ApoE}^{-/-}$mice exposed to CS. The levels of pro-inflammatory mediators such as MCP-1 (A) and KC (B) were measured by ELISA in lung homogenates of air- and CS-exposed $\mathrm{WT}$ and $\mathrm{ApoE}^{-/-}$mice. Data are shown as mean \pm SEM ( $n=3-4$ mice per group). ${ }^{*} P<$ $0.01,{ }^{* *} P<0.001$, significant compared with corresponding airexposed mice. ${ }^{+} p<0.05,{ }^{++} p<0.01$ significant compared with CSexposed WT mice. ${ }^{\#} P<0.05$, significant compared with air-exposed WT mice

vascular endothelial dysfunction [21,22,28]. Therefore, we assessed the lung levels of lipid peroxidation products (4-HNE and MDA) as a measure of increased oxidative stress in WT and $\mathrm{ApoE}^{-1-}$ mice exposed to CS. A significant increase in 4-HNE and MDA levels were observed in CS-exposed $\mathrm{ApoE}^{-/-}$mice lung compared to WT (Fig. 3). This result suggests that CS-induced oxidative stress and lipid peroxidation might be the causative factor for an increased inflammatory response, which would lead to the development of premature emphysema and vascular abnormalities in these mice.

\section{$\mathrm{ApoE}^{-/-}$mice show increased airspace enlargement and alterations in lung mechanical properties in response to CS exposure}

We measured the airspace enlargement and decline in lung function, which are the characteristics of pulmonary emphysema/COPD, in WT and $\mathrm{ApoE}^{-/-}$mice exposed to air or CS. ApoE ${ }^{-1-}$ mice exposed to CS showed a significant increase in alveolar size as compared to air- and CS-exposed WT mice (Fig. 4A, B). There was also a spontaneous airspace enlargement seen in $\mathrm{ApoE}^{-/-}$mice. The lung compliance (measured as lung function) was significantly increased in air- and CS-exposed ApoE ${ }^{-1-}$ mice compared to air- and CSexposed WT mice (Fig. 4C, D). The lung resistance was significantly lowered in air- and CS-exposed $\mathrm{ApoE}^{-1-}$ mice compared to air- and CS-exposed WT mice. These data suggest that lungs of $\mathrm{ApoE}^{-1-}$ mice have impaired alveologenesis and alveolar destruction with altered lung mechanical properties, which were augmented by acute CS exposure.

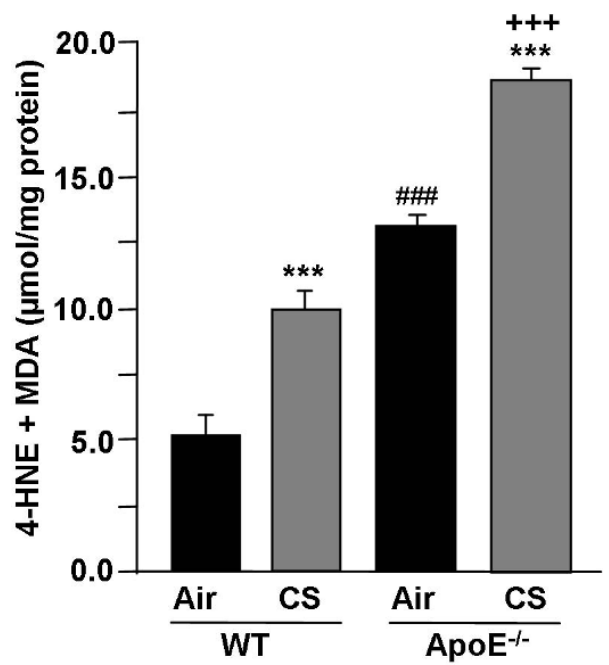

Figure 3 Levels of lipid peroxidation products (4-HNE and $\mathrm{MDA}$ ) in lungs of $\mathrm{ApoE}^{-/-}$mice exposed to CS. Levels of 4-HNE and MDA were measured spectrophotometrically in lung homogenates of WT and $\mathrm{ApoE}^{-1-}$ mice exposed to CS. Histograms represent mean \pm SEM of $n=3-4$ per group. ${ }^{* *} P<0.001$, significant compared with corresponding air-exposed mice. ${ }^{+++} p<$ 0.001 , significant compared with CS-exposed WT mice. ${ }^{\# \#} P<0.001$, significant compared with air-exposed WT mice.

ApoE $^{-/-}$mice show increased levels and activities of matrix metalloproteinases, and reduction of SIRT1 levels and activity as well as eNOS levels in lungs by CS

MMPs, particularly increased levels of MMP-9 and MMP-12, are involved in CS-mediated airspace enlargement/alveolar wall destruction (emphysema). Hence, we determined whether the levels and activities of MMP-9 and MMP-12 were altered in ApoE ${ }^{-/-}$mice after CS exposure. The levels of MMP-9 and MMP-12 were significantly increased in lungs of CS-exposed $\mathrm{ApoE}^{-/-}$ mice compared to that of WT mice (Fig. 5A-C). Similarly, there was a 1.8 and 2.2-fold increase in MMP-9 and MMP-12 activities respectively in lungs of WT mice exposed to CS as compared to air-exposed WT mice. Air-exposed ApoE ${ }^{-/}$mice showed a 1.6 and 1.8-fold increase in corresponding MMP-9 and MMP-12 activities in the lungs as compared to air-exposed WT mice, which was further augmented in CS-exposed $\mathrm{ApoE}^{-/-}$ mice (2.8-fold increase in MMP-9 activity and 2.6-fold increase in MMP-12 activity).

We determined the levels of SIRT1 and eNOS in lungs of $\mathrm{ApoE}^{-/-}$mice exposed to CS. The basal endogenous abundances of SIRT1 and eNOS were significantly decreased in $\mathrm{ApoE}^{-/-}$mice compared with WT mice (Fig. 6A-D). ApoE ${ }^{-/-}$mice exposed to CS showed further reduction in SIRT1 level and activity (Fig. 6E) and eNOS levels (Fig. 6B, D) compared to air- and CSexposed WT mice. Hence, CS-mediated reduction in SIRT1 and eNOS levels was associated with pulmonary 


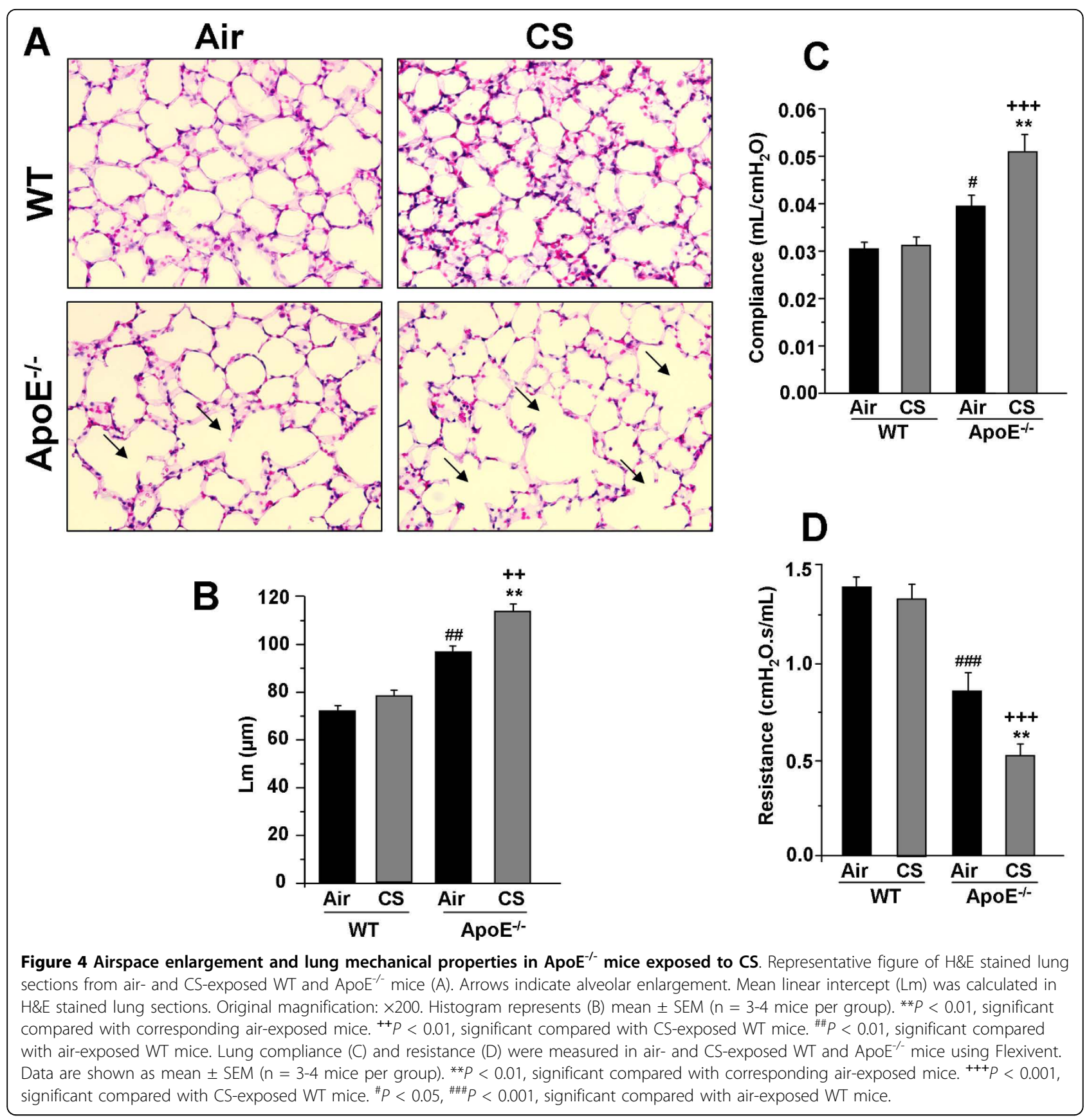

functional and morphological phenotype alterations in $\mathrm{ApoE}^{-1-}$ mice.

\section{Discussion}

Prolonged exposure to CS leads to the development of COPD associated with arterial stiffness, endothelial dysfunction and atherosclerosis-mediated cardiovascular diseases [1-5]. The lungs of $\mathrm{ApoE}^{-/-}$mice also have impaired alveologenesis with altered lung mechanical properties [18]. However, the underlying molecular mechanism of this pulmonary phenotype in $\mathrm{ApoE}^{-1-}$ by
$\mathrm{CS}$ is not known. We used $\mathrm{ApoE}^{-1-}$ mice to study the pulmonary phenotype in response to CS. We found that the air-exposed WT and $A \mathrm{PoE}^{-/-}$mice showed no change in neutrophil influx, whereas CS-exposed $\mathrm{ApoE}^{-/-}$mice had an increased neutrophil influx in BAL fluid compared to CS-exposed WT mice. The macrophage influx in lung interstitium was also significantly increased in lungs of CS-exposed $\mathrm{ApoE}^{-/-}$mice compared to CS-exposed WT or control ApoE ${ }^{-1-}$ mice. MCP-1 and KC (pro-inflammatory cytokines) are capable of recruiting macrophages and neutrophils 


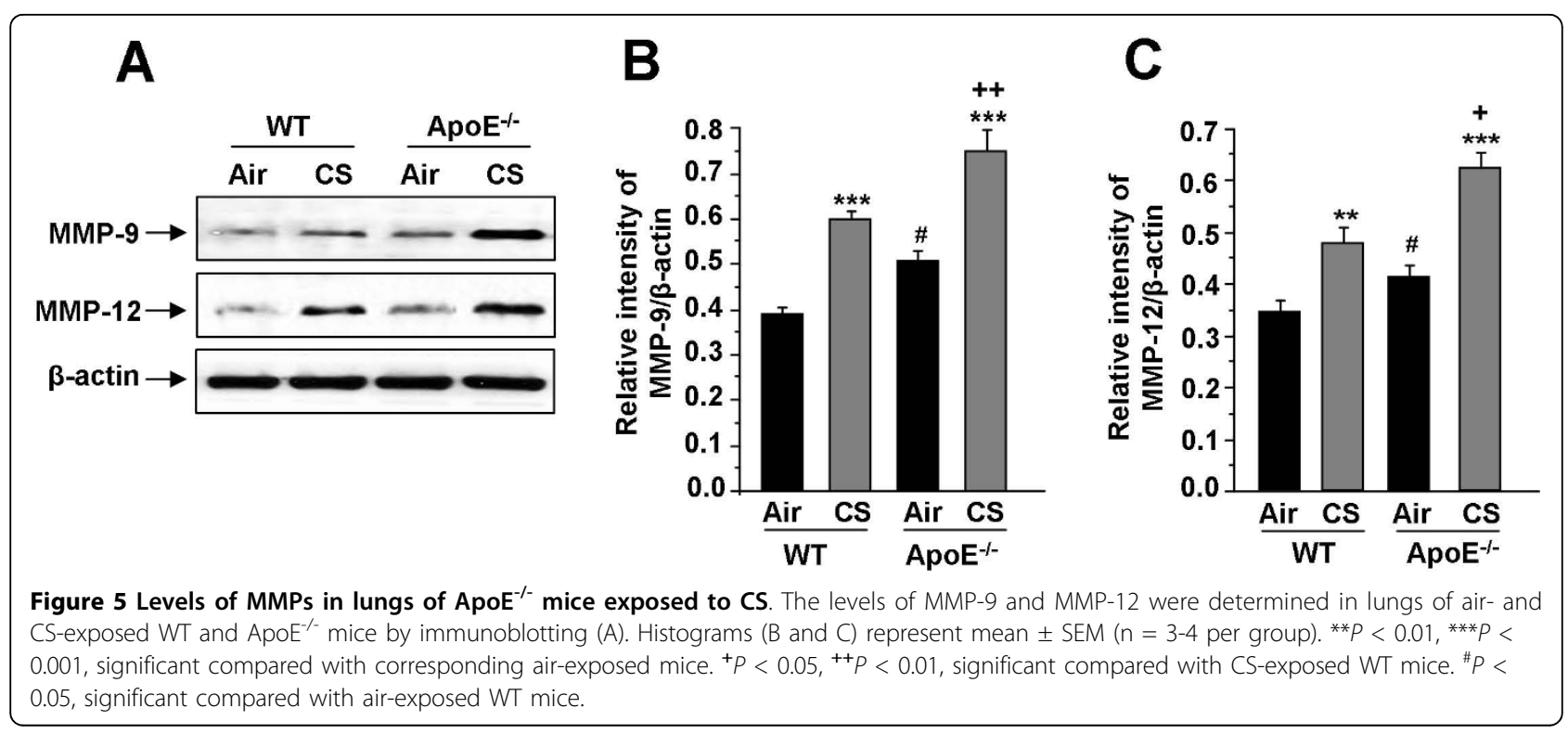

respectively into the lungs in the presence and absence of inflammatory stimuli $[29,30]$. The susceptibility of $\mathrm{ApoE}^{-1-}$ mice to CS-mediated increased inflammation was further confirmed by the increased levels of proinflammatory cytokine (MCP-1 and $\mathrm{KC}$ ) release in lungs of adult 12 weeks old $\mathrm{ApoE}^{-/-}$mice exposed to CS for acute period (3 days) when fed the regular/standard Chow-diet. Interestingly, air-exposed $\mathrm{ApoE}^{-/-}$mice also showed increased pro-inflammatory cytokine release possibly due to infiltrated macrophages in the lung, which was further increased in response to CS exposure. Previously, it has been shown that lungs of $\mathrm{ApoE}^{-/-}$mice

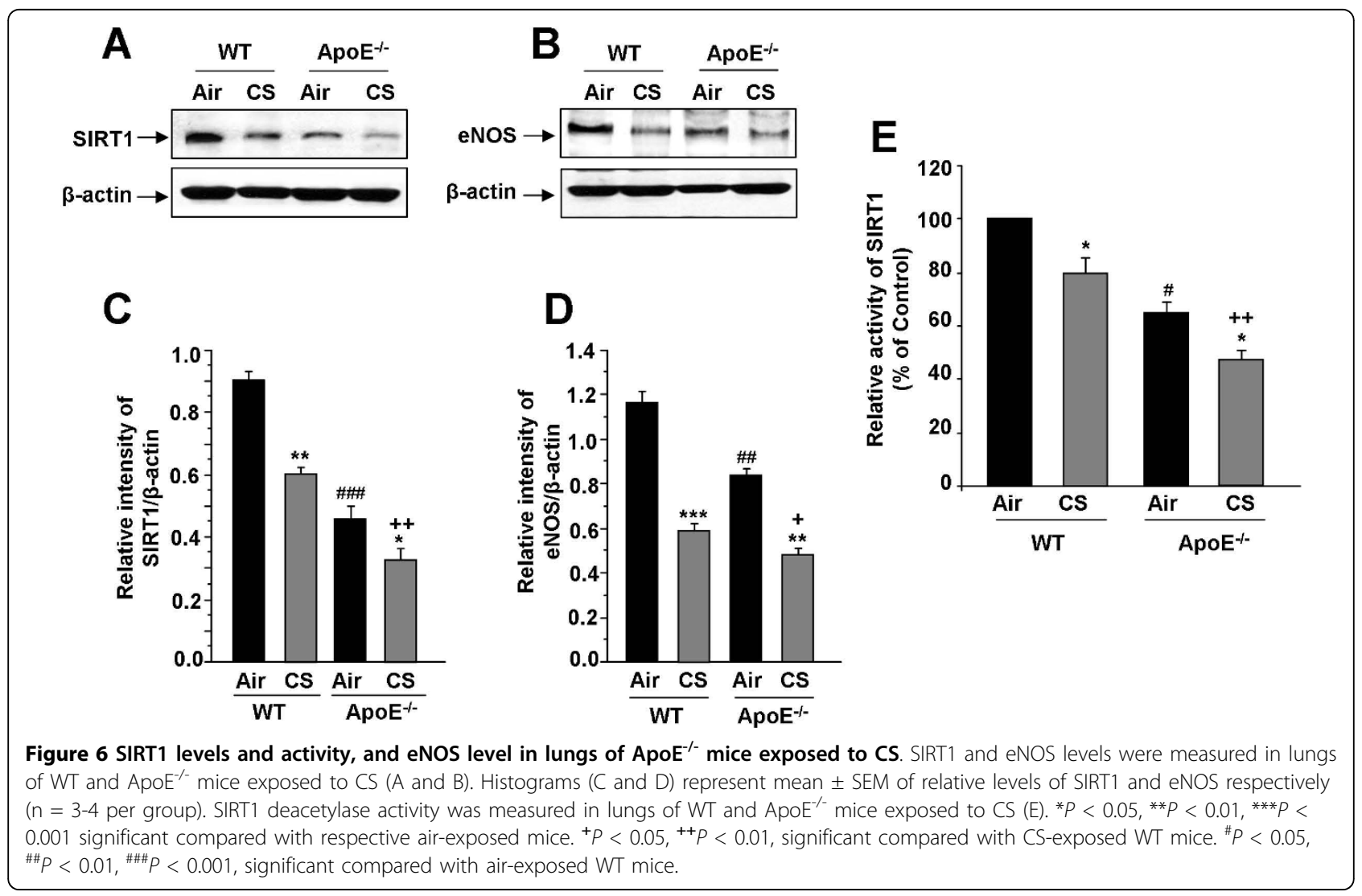


had increased levels of pro-inflammatory cytokine (TNF$\alpha$, IL-1) and expression of adhesion molecules, such as inter-cellular adhesion molecule-1 (ICAM-1) and vascular cell adhesion molecule-1 (VCAM-1) [31]. These findings suggest that $\mathrm{ApoE}^{-1-}$ mice are prone to develop atherosclerotic lesions by activation of proatherogenic molecules which are associated with augmented lung inflammatory response. However, it is not known whether $\mathrm{T}$ and $\mathrm{B}$ cells are involved in the inflammatory response seen in $\mathrm{ApoE}^{-/-}$mice, since these cells also play an important role in the development of emphysema/COPD in humans. Further studies are required to confirm this possibility.

CS either directly or indirectly induces the production of ROS such as superoxide anions, hydroxyl radicals and hydrogen peroxide. We have previously shown that the imbalance between oxidants and antioxidants are associated with lung inflammatory response and development of emphysema [21,22]. In the present study, CS exposure resulted in increased levels of lipid peroxidation products, as shown by the generation of 4-HNE and MDA in lungs of ApoE ${ }^{-1-}$ mice. It is possible that CS augments the generation of lipid peroxidation derived 4-HNE which would activate inflammatory signaling pathways in the lungs of $\mathrm{ApoE}^{-/-}$mice, thereby leading to an increased inflammatory response and development of premature emphysema in these mice.

Reduced $\mathrm{FEV}_{1}$ with airflow limitation is often associated with atherosclerosis and other cardiovascular morbidities [2-4]. Our data show increased airspace enlargement/alveolar destruction with altered lung compliance and resistance in air-exposed $\mathrm{ApoE}^{-/-}$mice, which were further aggravated in response to acute CS exposure. Since increased levels of MMPs, such as MMP-9 and MMP-12, are potentially involved in alveolar destruction associated with altered lung function, we measured the levels and activities of MMPs in lungs of $\mathrm{ApoE}^{-/-}$mice. ApoE ${ }^{-/-}$mice exposed to CS showed the increased levels of MMP-9 and MMP-12 in the lung compared to WT or control $\mathrm{ApoE}^{-/-}$mice. Furthermore, the activities of MMP-9 and MMP-12 were increased in lungs of CS-exposed $\mathrm{ApoE}^{-/-}$mice as compared to that of WT mice. It is possible that increased macrophage infiltration into the lungs in response to CS exposure may lead to elevated MMPs which might be the cause for airspace enlargement and lower lung function observed in these mice. It is noteworthy to mention here that $\mathrm{ApoE}^{-/-}$mice when fed with high cholesterol diet show increased inflammatory cell recruitment with enhanced MMP-9 activity [31,32]. Furthermore, overexpression of MMP-9 in $\mathrm{ApoE}^{-/-}$mice resulted in an increased smooth muscle cell infiltration (lesion maturation) and increased plaque formation in mouse aorta [32]. These findings suggest that CS-mediated induction of MMPs not only leads to increased alveolar destruction, but is also associated with the atherosclerotic plaque formation in these mice as evidenced earlier $[12,13]$.

It has been shown that eNOS regulates endothelial function and several components of the atherogenic process, such as vascular smooth muscle cell contraction, proliferation, platelet aggregation, and monocyte adhesion [27,33-35]. Previously, it has been shown that $\mathrm{ApoE}^{-/-}$mice have a deficiency of eNOS which is exhibited with high levels of atherosclerotic lesion formation $[36,37]$. In the present study, the eNOS level was measured in order to understand whether CS-mediated emphysema in $\mathrm{ApoE}^{-/-}$mice was associated with endothelial dysfunction. The basal abundance of eNOS was significantly decreased in the lungs of $\mathrm{ApoE}^{-/-}$mice compared to WT mice with further reduction in ApoE ${ }^{-/-}$mice exposed to CS. These data are supported by a previous study demonstrating the decreased eNOS level in $\mathrm{ApoE}^{-1-}$ mice exposed to ozone was associated with increased vascular dysfunction, oxidative stress, mitochondrial damage, and atherogenesis [38]. Furthermore, knockdown of eNOS in $\mathrm{ApoE}^{-1-}$ mice showed increased lesions area with peripheral coronary atherosclerosis with myocardial fibrosis compared with $\mathrm{ApoE}^{-/-}$alone [37]. These observations implicate that a reduction of eNOS leads to altered endothelial function in lung microvasculature and/or vascular disruption as well as atherogenesis.

Recently, we and others have shown that eNOS is regulated by acetylation/deacetylation via SIRT1 deacetylase or calorie restriction $[34,39,40]$. Previous studies have shown that CS causes reduction in SIRT1 levels/ activity by posttranslational modification such as alkylation/carbonylation, which was associated with increased proinflammatory gene expression [23,24,41]. Furthermore, calorie/dietary restriction or overexpression of SIRT1 in $\mathrm{ApoE}^{-1-}$ mice exhibited an anti-atherosclerosis effect by inhibiting oxidized low-density lipoprotein (LDL)-induced apoptosis, upregulation of eNOS expression and improved endothelium-dependent vasorelaxation $[42,43]$. Interestingly, the SIRT1 level and activity were significantly decreased in the lungs of $\mathrm{ApoE}^{-/}$ mice with further reduction in response to CS. Decreased SIRT1 levels and activity may lead to increased acetylation and inactivation of eNOS in the lungs of $\mathrm{ApoE}^{-/-}$mice exposed to CS culminating endothelial dysfunction. However, further studies are required to study how post-translational modifications (e.g. phospho-acetylation) affect its activity in response to CS exposure. This may be one of the reasons that $\mathrm{ApoE}^{-/-}$mice show signs of early aging [11] as SIRT1 is an anti-aging protein [24]. Hence, SIRT1 activation (and $\mathrm{NAD}^{+}$replenishment) may not only activate eNOS but will also inhibit endothelial cell senescence, 
atherosclerosis and inflammatory response in the lung $[23,44,45]$. This is further validated by SIRT1 activation or calorie restriction in $\mathrm{ApoE}^{-1-}$ mice leads to protection against atherosclerosis progression by upregulating eNOS [43-45]. Interestingly, our preliminary data showed that overexpression of SIRT1 in $\mathrm{ApoE}^{-1-}$ mice in double transgenic mice protected, whereas knockdown of SIRT1 in $\mathrm{ApoE}^{-/-}$mice aggravated the lung phenotype (inflammation and emphysema).

In summary, our study shows the augmented inflammatory response, increased oxidative stress, and airspace enlargement with altered mechanical properties in lungs of $\mathrm{ApoE}^{-1-}$ mice in response to CS, which was associated with increased MMPs, reduced SIRT1 activity and eNOS levels. These mice have an accumulation of excess lipids laden in blood and pulmonary arteries/lung microvasculature which can undergo rapid oxidation by CS-derived free radicals and oxidants leading to the generation of secondary oxidized lipid mediators/peroxidation products/signaling molecules both systemically and locally. This will trigger alterations in SIRT1, eNOS and abnormal inflammatory responses leading to pulmonary functional and morphological phenotype. This may be one of the mechanisms linking CS-mediated accelerated decline in lung function and aging in comorbidities of cardiopulmonary diseases [46].

\section{Abbreviations}

ApoE: apolipoprotein E; COPD: chronic obstructive pulmonary diseases; CS: cigarette smoke; eNOS: endothelial nitric oxide synthase; 4-HNE: 4-hydroxy-2nonenal; MDA: malondialdehyde; MMPs: matrix metalloproteinases.

\section{Acknowledgements}

This study was supported by the NIH 1R01HL085613, 1R01HL097751, 1 R01HL092842 and NIEHS ES-01247. We thank Dr. Donald Massaro (Georgetown University) for useful discussions.

\section{Authors' contributions}

GA contributed in the study design and planning, and performed the experiments. JH, IKS and HY participated and coordinated in completing the study. GA wrote the first draft of the manuscript. IR supervised the study and contributed in data discussions and correcting the drafts. Furthermore, IR conceived the study, contributed in the study design, planning and revised the manuscript. All authors read and approved the final manuscript.

\section{Competing interests}

The authors declare that they have no competing interests.

Received: 12 May 2010 Accepted: 22 July 2010 Published: 22 July 2010

\section{References}

1. Barnes PJ, Celli BR: Systemic manifestations and comorbidities of COPD. Eur Respir J 2009, 33:1165-1185.

2. Iwamoto H, Yokoyama A, Kitahara Y, Ishikawa N, Haruta Y, Yamane K, Hattori N, Hara H, Kohno N: Airflow limitation in smokers is associated with subclinical atherosclerosis. Am J Respir Crit Care Med 2009, 179:35-40.

3. Maclay JD, McAllister DA, MacNee W: Cardiovascular risk in chronic obstructive pulmonary disease. Respirology 2007, 12:634-641.

4. Sin DD, Wu L, Man SF: The relationship between reduced lung function and cardiovascular mortality: a population-based study and a systematic review of the literature. Chest 2005, 127:1952-1959.
5. Sin DD, Wu L, Man SF: Systemic inflammation and mortality in chronic obstructive pulmonary disease. Can J Physiol Pharmacol 2007, 85:141-147.

6. Yang Z, Knight CA, Mamerow MM, Vickers K, Penn A, Postlethwait EM, Ballinger SW: Prenatal environmental tobacco smoke exposure promotes adult atherogenesis and mitochondrial damage in apolipoprotein E-/mice fed a chow diet. Circulation 2004, 110:3715-3720.

7. Ota Y, Kugiyama K, Sugiyama S, Ohgushi M, Matsumura T, Doi H, Ogata N, Oka $\mathrm{H}$, Yasue $\mathrm{H}$ : Impairment of endothelium-dependent relaxation of rabbit aortas by cigarette smoke extract-role of free radicals and attenuation by captopril. Atherosclerosis 1997, 131:195-202.

8. Bertelli AA, Das DK: Grapes, wines, resveratrol, and heart health. J Cardiovasc Pharmacol 2009, 54:468-76.

9. Kamholz KS: Wine, Spirits and the Lung: Good, Bad or Indifferent? Trans Am Clin Climatol Assoc 2006, 117:129-145.

10. Mahley RW: Apolipoprotein E: cholesterol transport protein with expanding role in cell biology. Science 1988, 240:622-630.

11. Ang LS, Cruz RP, Hendel A, Granville DJ: Apolipoprotein E, an important player in longevity and age-related diseases. Exp Gerontol 2008 43:615-622.

12. Schroeter MR, Sawalich M, Humboldt T, Leifheit M, Meurrens $K$, Berges $A$, Xu H, Lebrun S, Wallerath T, Konstantinides S, Schleef R, Schaefer K: Cigarette smoke exposure promotes arterial thrombosis and vessel remodeling after vascular injury in apolipoprotein E-deficient mice. J Vasc Res 2008, 45:480-492.

13. Von Holt K, Lebrun S, Stinn W, Conroy L, Wallerath T, Schleef R: Progression of therosclerosis in the Apo E-/- model: 12-month exposure to cigarette mainstream smoke combined with high-cholesterol/fat diet. Atherosclerosis 2009, 205:135-143.

14. Knight-Lozano CA, Young CG, Burow DL, Hu ZY, Uyeminami D, Pinkerton KE, Ischiropoulos $\mathrm{H}$, Ballinger SW: Cigarette smoke exposure and hypercholesterolemia increase mitochondrial damage in cardiovascular tissues. Circulation 2002, 105:849-854.

15. Tani S, Dimayuga PC, Anazawa T, Chyu KY, Li H, Shah PK, Cercek B: Aberrant antibody responses to oxidized LDL and increased intimal thickening in apoE $\mathrm{E}^{-/-}$mice exposed to cigarette smoke. Atherosclerosis 2004, 175:7-14.

16. Gairola CG, Drawdy ML, Block AE, Daugherty A: Sidestream cigarette smoke accelerates atherogenesis in apolipoprotein E-/- mice. Atherosclerosis 2001, 156:49-55.

17. Biswas SK, Newby DE, Rahman I, Megson IL: Depressed glutathione synthesis precedes oxidative stress and atherogenesis in Apo-E(-/-) mice. Biochem Biophys Res Commun 2005, 338:1368-1373.

18. Massaro D, Massaro GD: Apoetm1Unc mice have impaired alveologenesis, low lung function, and rapid loss of lung function. Am J Physiol Lung Cell Mol Physiol 2008, 294:L991-L997.

19. Zhang SH, Reddick RL, Piedrahita JA, Maeda N: Spontaneous hypercholesterolemia and arterial lesions in mice lacking apolipoprotein E. Science 1992, 258:468-471.

20. Whitman SC: A practical approach to using mice in atherosclerosis research. Clin Biochem Rev 2004, 25:81-93.

21. Rajendrasozhan S, Chung S, Sundar IK, Yao H, Rahman I: Targeted disruption of NF- $\kappa \mathrm{B} 1$ (p50) augments cigarette smoke-induced lung inflammation and emphysema in mice: a critical role of p50 in chromatin remodeling. Am J Physiol Lung Cell Mol Physiol 2010, 298: L197-L209.

22. Yao H, Edirisinghe I, Rajendrasozhan S, Yang SR, Caito S, Adenuga D, Rahman I: Cigarette smoke-mediated inflammatory and oxidative responses are strain-dependent in mice. Am J Physiol Lung Cell Mol Physiol 2008, 294:L1174-L1186.

23. Yang SR, Wright J, Bauter M, Seweryniak K, Kode A, Rahman I: Sirtuin regulates cigarette smoke-induced proinflammatory mediator release via RelA/p65 NF-kappaB in macrophages in vitro and in rat lungs in vivo: implications for chronic inflammation and aging. Am J Physiol Lung Cell Mol Physiol 2007, 292:L567-L576.

24. Rajendrasozhan S, Yang SR, Kinnula VL, Rahman I: SIRT1, an antiinflammatory and antiaging protein, is decreased in lungs of patients with chronic obstructive pulmonary disease. Am J Respir Crit Care Med 2008, 177:861-870

25. Suga M, lyonaga K, Okamoto T, Gushima Y, Miyakawa H, Akaike T, Ando M: Characteristic elevation of matrix metalloproteinase activity in idiopathic interstitial pneumonias. Am J Respir Crit Care Med 2000, 162:1949-1956. 
26. Sun Q, Wang A, Jin X, Natanzon A, Duquaine D, Brook RD, Aguinaldo JG, Fayad ZA, Fuster V, Lippmann M, Chen LC, Rajagopalan S: Long-term air pollution exposure and acceleration of atherosclerosis and vascular inflammation in an animal model. JAMA 2005, 294:3003-3010.

27. Araujo JA, Barajas B, Kleinman M, Wang X, Bennett BJ, Gong KW, Navab M Harkema J, Sioutas C, Lusis AJ, Nel AE: Ambient particulate pollutants in the ultrafine range promote early atherosclerosis and systemic oxidative stress. Circ Res 2008, 102:589-596.

28. Edirisinghe I, Yang SR, Yao H, Rajendrasozhan S, Caito S, Adenuga D, Wong C, Rahman A, Phipps RP, Jin ZG, Rahman I: VEGFR-2 inhibition augments cigarette smoke-induced oxidative stress and inflammatory responses leading to endothelial dysfunction. FASEB J 2008, 22:2297-2310.

29. Fuentes ME, Durham SK, Swerdel MR, Lewin AC, Barton DS, Megill JR, Bravo R, Lira SA: Controlled recruitment of monocytes and macrophages to specific organs through transgenic expression of monocyte chemoattractant protein-1. J Immunol 1995, 155:5769-5776.

30. Lira SA, Zalamea P, Heinrich JN, Fuentes ME, Carrasco D, Lewin AC, Barton DS, Durham S, Bravo R: Expression of the chemokine N51/KC in the thymus and epidermis of transgenic mice results in marked infiltration of a single class of inflammatory cells. J Exp Med 1994, 180:2039-2048.

31. Naura AS, Hans CP, Zerfaoui M, Errami Y, Ju J, Kim H, Matrougui K, Kim JG, Boulares $\mathrm{AH}$ : High-fat diet induces lung remodeling in ApoE-deficient mice: an association with an increase in circulatory and lung inflammatory factors. Lab Invest 2009, 89:1243-1251.

32. Lemaitre V, Kim HE, Forney-Prescott M, Okada Y, D'Armiento J: Transgenic expression of matrix metalloproteinase- 9 modulates collagen deposition in a mouse model of atherosclerosis. Atherosclerosis 2009, 205:107-112.

33. Edirisinghe I, Arunachalam G, Wong C, Yao H, Rahman A, Phipps RP, Jin ZG, Rahman I: Cigarette Smoke-induced Oxidative/Nitrosative Stress Impairs VEGF- and Fluid Shear Stress-Mediated Signaling in Endothelial Cells. Antioxid Redox Signal 2010, 12:1355-1369.

34. Arunachalam G, Yao H, Sundar IK, Caito S, Rahman I: SIRT1 regulates oxidant- and cigarette smoke-induced eNOS acetylation in endothelial cells: Role of resveratrol. Biochem Biophys Res Commun 2010, 393:66-72.

35. Takaya T, Hirata K, Yamashita T, Shinohara M, Sasaki N, Inoue N, Yada T, Goto M, Fukatsu A, Hayashi T, Alp NJ, Channon KM, Yokoyama M, Kawashima S: A specific role for eNOS-derived reactive oxygen species in atherosclerosis progression. Arterioscler Thromb Vasc Biol 2007, 27:1632-1637.

36. Knowles JW, Reddick RL, Jennette JC, Shesely EG, Smithies O, Maeda N: Enhanced atherosclerosis and kidney dysfunction in eNOS(-/-)Apoe(-/-) mice are ameliorated by enalapril treatment. J Clin Invest 2000, 105:451-458.

37. Kuhlencordt PJ, Gyurko R, Han F, Scherrer-Crosbie M, Aretz TH, Hajjar R, Picard MH, Huang PL: Accelerated atherosclerosis, aortic aneurysm formation, and ischemic heart disease in apolipoprotein E/endothelial nitric oxide synthase double-knockout mice. Circulation 2001, 104:448-454.

38. Chuang GC, Yang Z, Westbrook DG, Pompilius M, Ballinger CA, White CR, Krzywanski DM, Postlethwait EM, Ballinger SW: Pulmonary ozone exposure induces vascular dysfunction, mitochondrial damage, and atherogenesis. Am J Physiol Lung Cell Mol Physiol 2009, 297:L209-L216.

39. Nisoli E, Tonello C, Cardile A, Cozzi V, Bracale R, Tedesco L, Falcone S, Valerio A, Cantoni O, Clementi E, Moncada S, Carruba MO: Calorie restriction promotes mitochondrial biogenesis by inducing the expression of eNOS. Science 2005, 310:314-317.

40. Mattagajasingh I, Kim CS, Naqvi A, Yamamori T, Hoffman TA, Jung SB, DeRicco J, Kasuno K, Irani K: SIRT1 promotes endothelium-dependent vascular relaxation by activating endothelial nitric oxide synthase. Proc Natl Acad Sci USA 2007, 104:14855-14860.

41. Caito S, Rajendrasozhan S, Cook S, Chung S, Yao H, Friedman AE, Brookes PS, Rahman I: SIRT1 is a redox-sensitive deacetylase that is posttranslationally modified by oxidants and carbonyl stress. FASEB J PMID 2010, 20385619, Apr 12 Epub ahead of print.

42. Zhang QJ, Wang Z, Chen HZ, Zhou S, Zheng W, Liu G, Wei YS, Cai H, Liu DP, Liang CC: Endothelium-specific overexpression of class III deacetylase SIRT1 decreases atherosclerosis in apolipoprotein E-deficient mice. Cardiovasc Res 2008, 80:191-199.

43. Guo Z, Raymundo FM, Yang H, Ikeno Y, Nelson J, Diaz V, Richardson A, Reddick R: Dietary restriction reduces atherosclerosis and oxidative stress in the aorta of apolipoprotein E-deficient mice. Mech Ageing Dev 2002, 123:1121-1131.

44. Yu W, Fu YC, Chen CJ, Wang X, Wang W: SIRT1: a novel target to prevent atherosclerosis. J Cell Biochem 2009, 108:10-13.

45. Ota H, Eto M, Ogawa S, lijima K, Akishita M, Ouchi Y: SIRT1/eNOS axis as a potential target against vascular senescence, dysfunction and atherosclerosis. J Atheroscler Thromb 2010, 17:431-435.

46. Ukena C, Mahfoud F, Kindermann M, Kindermann I, Bals R, Voors AA, van Veldhuisen DJ, Bohm M: The Cardiopulmonary continuum systemic inflammation as 'common soil' of heart and lung disease. Int J Cardiol 2010, PMID 20570377, Jun 4.

doi:10.1186/1476-9255-7-34

Cite this article as: Arunachalam et al: Emphysema is associated with increased inflammation in lungs of atherosclerosis-prone mice by cigarette smoke: implications in comorbidities of COPD. Journal of Inflammation 2010 7:34.

\section{Submit your next manuscript to BioMed Central and take full advantage of:}

- Convenient online submission

- Thorough peer review

- No space constraints or color figure charges

- Immediate publication on acceptance

- Inclusion in PubMed, CAS, Scopus and Google Scholar

- Research which is freely available for redistribution

Submit your manuscript at www.biomedcentral.com/submit
C Biomed Central 